\title{
Pyrolysis of Cellulose in a Vacuum ${ }^{12}$
}

\author{
S. L. Madorsky, V. E. Hart, and S. Straus
}

\begin{abstract}
Samples of cotton, cotton hydrocellulose, and viscose rayon, both by themselves and impregnated with sodium carbonate or sodium chloride, were pyrolyzed at $250^{\circ}$ to $397^{\circ} \mathrm{C}$ in a high vacuum. The volatile products were fractionated and the fractions analyzed in the mass spectrometer and by infrared absorption. The volatile fractions consisted mainly of $\mathrm{CO}, \mathrm{CO}_{2}$, water, and levoglucosan (tar). The residue consisted mainly of carbon (char). Impregnation of the cellulosic materials with salts caused a decrease in the yield of tar and an increase in the yields of $\mathrm{CO}, \mathrm{CO}_{2}, \mathrm{H}_{2} \mathrm{O}$, and char. Rates of thermal degradation of the same materials were investigated in the range $245^{\circ}$ to $305^{\circ} \mathrm{C}$ by a loss-of-weight method, using a very sensitive tungsten spring balance enclosed in a vacuum. Plots of rates of loss of weight versus percentage of loss of weight, in the case of pure cellulosic materials, pass through maxima at about 13 to 23 percent loss of weight, then drop gradually to the carbonization end point. In the case of samples impregnated with sodium carbonate or sodium chloride, the initial rates of loss of weight are very high, but drop rapidly to the carbonization end point. The activation energies of thermal degradation of the pure cellulosic materials are much greater than those of the same materials impregnated with sodium carbonate or sodium chloride.
\end{abstract}

\section{Introduction}

An investigation of the thermal degradation or pyrolysis of cellulose in a vacuum was undertaken in connection with the problem of rendering cellulosic materials used in fabrics flame-resistant. Flaming of these materials takes place in two principal consecutive steps: (1) the cellulose first degrades under the influence of heat to form volatile and nonvolatile products; (2) the flammable constituents of the products ignite and the heat evolved promotes further decomposition of the cellulose. In rendering cellulosic materials resistant to flaming, the conditions of degradation are so altered as to increase the amount of the nonflammable products at the expense of the flammable products.

This paper deals with the first of the two steps enumerated above. The advantages of conducting pyrolysis in a vacuum, instead of in air or in an inert gas, are that the degradation products are prevented from reacting with oxygen (in the case of air) and that the volatile products are more quickly and completely removed from the hot zone, where they might otherwise undergo secondary reactions. In a vacuum the volatile products are more easily collected and fractionated for analysis.

Pyrolysis of cellulose at reduced pressures has been reported by several investigators $[1,2,3,4] .^{3}$ Their results indicate the formation of tar, char, $\mathrm{H}_{2} \mathrm{O}$, $\mathrm{CO}_{2}$, and $\mathrm{CO}$ in various vields, depending on conditions of pyrolysis. In this investigation a vacuum of $10^{-3}$ to $10^{-5} \mathrm{~mm} \mathrm{Hg}$ was maintained during pyrolysis, and a study was made of the nature and proportion of the various products and also of the rates of degradation of pure cellulosic materials with or without additives. A considerable amount of research has been conducted in recent years at the $\mathrm{Bu}-$

1 This work was performed as a part of the research project sponsored by the Office of Quartermaster General, Department of the Army

${ }_{2}$ This paper was presented at the 128th National Meeting of the American Chemical Society in Minneapolis, Minn., September 12 to 16, 1955.

${ }_{3}$ Figures in brackests indicate the literature references at the end of this paper reau on the thermal degradation of vinyl, butadiene, and aromatic polymers; the methods and apparatus developed and used in this research have now been applied to the study of thermal degradation of cellulose. The method can be divided into two parts:

(1) Pyrolysis of a small sample in an evacuated apparatus, and subsequent investigation of the decomposition products.

(2) Determination of rates of thermal degradation at several temperatures, and calculation of the activation energies of the degradation reactions involved.

\section{Materials Used}

Three forms of cellulose were used: cotton cellulose, cotton hydrocellulose, and viscose rayon. The cotton, which was an Empire cotton obtained from the Southern Utilization Branch of the U. S. Department of Agriculture, was dewaxed by extraction with boiling alcohol. It was freed from pectic substances by immersion in boiling 1-percent sodium hydroxide in the absence of air for $2 \mathrm{hr}$, washed in distilled water, neutralized with dilute acetic acid, again washed in water, and dried in air at room temperature. The hydrocellulose was obtained by immersion of a portion of the purified cotton in $6 \mathrm{~N} \mathrm{HCl}$ for approximately $15 \mathrm{hr}$. After washing with distilled water to remove the acid, the hydrocellulose was dried in air at room temperature. The viscose rayon was a commercial yarn, 900 denier, 100 filament. It was washed in warm dilute aqueous ammonia, rinsed in warm water, and dried in air at room temperature. ${ }^{4}$

In order to determine the amount of moisture and other volatiles adsorbed on the cellulosic materials, samples were "dried" to a constant weight in a vacuum at $100^{\circ} \mathrm{C}$. It was found that this could be accomplished in about $60 \mathrm{~min}$. Losses, in percentages of dry samples, were: 3.7, 4.1, and 8.6, for

${ }_{4}$ The authors are indebted to Florence H. Forziati of the Textiles Section of the Bureau for supplying the purified cotton, hydrocellulose, and rayon. 
cotton, hydrocellulose, and viscose rayon, respectively. In the actual pyrolysis experiments, the samples were dried in the above manner in the vacuum apparatus and the volatiles were pumped off prior to pyrolysis. The original weights of the samples were corrected for the above determined weight losses.

In some of the experiments, samples of cotton impregnated with $\mathrm{NaCl}$ or $\mathrm{Na}_{2} \mathrm{CO}_{3}$ and viscose rayon impregnated with $\mathrm{Na}_{2} \mathrm{CO}_{3}$ were used. The cellulose was impregnated with the salt in the following manner: A weighted amount of cellulose was placed in the container in which it was to be pyrolyzed. A weighed amount of salt was added to the same container. A small amount of water was then added and the water evaporated in an oven at about $80^{\circ} \mathrm{C}$. Drying of the sample and additive was then completed in a vacuum in the same manner as for the nonimpregnated samples. All calculations of losses, yields, residues, etc., were made on the basis of dry celluloses.

\section{Pyrolysis}

\subsection{Apparatus and Experimental Procedure}

In order to obtain a detailed analysis of the volatile products of pyrolysis, these were separated into fractions. The following volatile and nonvolatile fractions were collected:

1. Residue.

2. Fraction $V_{\mathrm{pyr}}$, volatile at the temperature of pyrolysis, but not at $25^{\circ} \mathrm{C}$.

3. Fraction $\mathrm{V}_{25}$, volatile at $25^{\circ} \mathrm{C}$, but not at $-80^{\circ} \mathrm{C}$.

4. Fraction $\dot{\mathrm{V}}_{-80}$, volatile at $-80^{\circ} \mathrm{C}$, but not at $-190^{\circ} \mathrm{C}$.

5. Fraction $\mathrm{V}_{-190}$, volatile at $-190^{\circ} \mathrm{C} .^{5}$

In previous work [5] on pyrolysis of polymers, fractions $\mathrm{V}_{\text {pyr }}, \mathrm{V}_{25}, \mathrm{~V}_{-80}$, and
$\mathrm{V}_{-190}$ were designated as fractions II, IIIB, IUA, and IV, respectively.
The pyrolysis apparatus is the same as that used in the thermal degradation of polytetrafluoroethylene [6], and is shown diagrammatically in figure 1.

In figure 1, A is a quartz tube, closed at one end and fitted into a larger quartz tube, B, also closed at one end. Tube B is attached to the vacuum system by means of a ground joint, C. A vacuum of about $10^{-3} \mathrm{~mm}$ of mercury could be obtained by means of a rotary oil pump, not shown in the figure, a liquid nitrogen-cooled trap, P, and a mercury-diffusion pump E. A cylindrical electric heater, not shown in the figure, could be moved in a fixed horizontal position so that tube A fitted approximately in the center of the heater muffle. The temperature was measured by means of a platinum versus platinum-10 percent rhodium thermocouple fixed permanently in the muffle of the heater, so that when the heater was moved in position for pyrolysis, the thermocouple came in contact with tube B approximately at a point where the sample was located in tube $A$ near its closed end. The heater was so constructed that an essentially uniform temperature could be maintained over the entire specimen. The temperature could be maintained within $\pm 0.5 \mathrm{deg} \mathrm{C}$ at pyrolysis temperatures.

After the cellulose specimen was placed in tube $A$ and the tube inserted into tube B, the apparatus was evacuated overnight. When the heater, which had been kept at the desired temperature, but away from the apparatus overnight, was moved into position, tube A reached the desired temperature within a few minutes.

During pyrolysis the apparatus was cut off from the evacuation pump by means of stopcock $\mathrm{D}$, while the mercury diffusion pump $\mathrm{E}$ remained in operation. The combined volatile fractions $\mathrm{V}_{25}, \mathrm{~V}_{-80}$, and $V_{-190}$ were confined between $\mathrm{D}$ and $\mathrm{E}$. The mercury pump was rated to hold $25-\mathrm{mm}$ back pressure, with a high vacuum on the inlet side; it was actually operated at a back pressure of not over

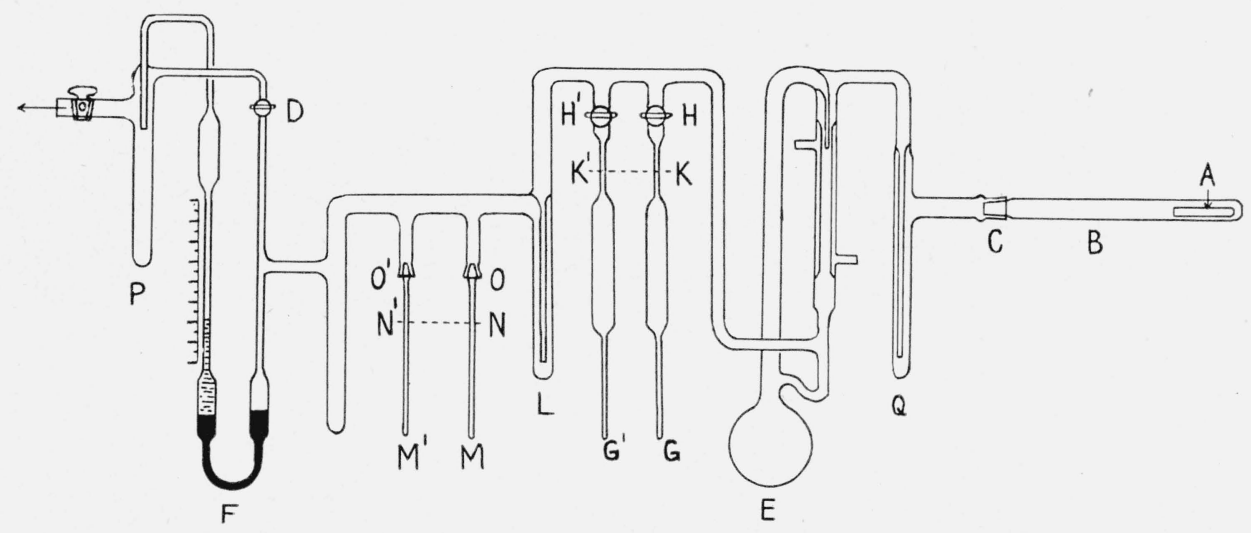

Figure 1. Apparatus for the study of thermal degradation of cellulosic materials.

A, Small quartz tube in which the sample is placed; B, large quartz tube; E, mercury diffusion pump; F, multiplying manometer; $\mathrm{G}_{,} \mathrm{G}^{\prime}$, tubes for collecting fraction $\mathrm{V}_{-190}$; L, trap; $\mathrm{M}, \mathrm{M}^{\prime}$, tubes for collecting fractions $\mathrm{V}_{25}$ and $\mathrm{V}_{-80}$; $\mathrm{P}$, liquid nitrogen cooled trap. 
$6 \mathrm{~mm}$. The pressure was measured in the calibrated space between this mercury pump and stopcock D by means of a multiplying manometer, $\mathrm{F}$, containing a low-vapor-pressure silicone oil in the left arm of the manometer, above a mercury column.

A sample of the gaseous fraction $V_{-190}$, noncondensable at the temperature of liquid nitrogen, was collected for analysis at the end of an experiment in the following manner. Liquid nitrogen was placed around trap L. The condensable material, consisting of combined fractions $V_{-80}$ and $V_{25}$, was drawn into L, and a sample of the remaining gaseous fraction $\mathrm{V}_{-190}$ was then taken for analysis in $60-\mathrm{ml}$ tube $\mathrm{G}$ or $\mathrm{G}^{\prime}$ by sealing off the tube at $\mathrm{K}$ or $\mathrm{K}^{\prime}$. The weight of fraction $V_{-190}$ was calculated from its volume, pressure, and composition.

After evacuating the excess fraction $V_{-190}$, the material that condensed in trap L was separated into two fractions, $V_{-80}$ and $V_{25}$, with the aid of dry ice. These fractions were collected by means of liquid nitrogen in $3-\mathrm{mm}$ tubes $\mathrm{M}$ and $\mathrm{M}^{\prime}$, which were attached to the vacuum system by means of ground joints $\mathrm{O}$ and $\mathrm{O}^{\prime}$. The tubes were sealed at $\mathrm{N}$ and $\mathrm{N}^{\prime}$, weighed, and the contents analyzed in the mass spectrometer.

Fraction $\mathrm{V}_{\mathrm{pyr}}$, volatile at the temperature of pyrolysis but not at room temperature, deposited during pyrolysis as a yellowish tarry material in the quartz tube B just outside the heater. It was dissolved in methanol, transferred into a weighing bottle, the solvent evaporated, and the tarry material was then weighed.

The nonvolatile residue remaining in tube $A$ was weighed in a weighing bottle. The total recovery weight of the products volatilized in each pyrolysis experiment was within a few tenths of a milligram of the loss in weight of the original dry sample. All weighings were made on a semimicro balance.

\subsection{Results of Pyrolysis}

Results of pyrolysis experiments are shown in table 1. Experiments 2a to $2 \mathrm{~g}$, inclusive, were carried out in consecutive steps on the same specimen

TARLE 1. Pyrolysis of cellulose in a vacuum

\begin{tabular}{|c|c|c|c|c|c|c|c|c|c|c|}
\hline \multirow{2}{*}{$\begin{array}{l}\text { Experi- } \\
\text { ment }\end{array}$} & \multirow{2}{*}{$\begin{array}{l}\text { Temper- } \\
\text { ature }\end{array}$} & \multirow{2}{*}{$\begin{array}{l}\text { Weight } \\
\text { of } \\
\text { sample }\end{array}$} & \multicolumn{2}{|c|}{ Duration } & \multicolumn{2}{|c|}{ Volatilization } & \multicolumn{4}{|c|}{$\begin{array}{l}\text { Volatile fractions, of total volatilized } \\
\text { part, for step }\end{array}$} \\
\hline & & & For step & $\underset{\text { tive }}{\text { Cumula- }}$ & For step & $\underset{\text { tive }}{\text { Cumula- }}$ & $\begin{array}{l}\mathrm{V}_{\mathrm{pyr}} \\
(\mathrm{Tar})\end{array}$ & $\begin{array}{c}\mathrm{V}_{25} \\
\left(\mathrm{H}_{2} \mathrm{O}\right)\end{array}$ & $\stackrel{\mathrm{V}_{-80}}{\left(\mathrm{CO}_{2}\right)}$ & $\begin{array}{l}\mathrm{V}_{-190} \\
(\mathrm{CO})\end{array}$ \\
\hline \multicolumn{11}{|c|}{ COTTON } \\
\hline $\begin{array}{l}1 \\
2 \mathrm{a} \\
2 \mathrm{~b} \\
2 \mathrm{c} \\
2 \mathrm{~d} \\
2 \mathrm{e} \\
2 \mathrm{f} \\
2 \mathrm{~g} \\
3 \\
4\end{array}$ & $\begin{array}{l}{ }^{\circ} C \\
250 \\
280 \\
280 \\
280 \\
280 \\
280 \\
280 \\
280 \\
321 \\
397\end{array}$ & $\begin{array}{c}m g \\
49.1 \\
83.3 \\
83.3 \\
83.3 \\
83.3 \\
83.3 \\
83.3 \\
83.3 \\
39.5 \\
13.8\end{array}$ & $\begin{array}{r}\min \\
300 \\
38 \\
58 \\
53 \\
100 \\
77 \\
180 \\
155 \\
9 \\
159\end{array}$ & $\begin{array}{r}\min \\
300 \\
38 \\
96 \\
149 \\
249 \\
326 \\
506 \\
661 \\
9 \\
159\end{array}$ & $\begin{array}{r}\% \\
2.7 \\
3.3 \\
7.0 \\
9.1 \\
15.9 \\
9.8 \\
16.7 \\
7.8 \\
22.0 \\
91.4\end{array}$ & $\begin{array}{r}\% \\
2.7 \\
3.3 \\
10.3 \\
19.4 \\
35.3 \\
45.1 \\
61.8 \\
69.6 \\
22.0 \\
91.4\end{array}$ & $\begin{array}{c}\% \\
26.3 \\
33.9 \\
55.9 \\
63.8 \\
70.2 \\
70.8 \\
65.2 \\
69.6\end{array}$ & \begin{tabular}{c}
$\%$ \\
53.9 \\
50.7 \\
36.1 \\
29.6 \\
\hdashline 23.6 \\
21.9 \\
28.2 \\
22.5
\end{tabular} & \begin{tabular}{r}
$\%$ \\
12.0 \\
10.5 \\
6.0 \\
5.4 \\
\hdashline 4.7 \\
5.5 \\
4.3 \\
6.2
\end{tabular} & $\begin{array}{r}\% \\
7.8 \\
4.9 \\
2.0 \\
1.2 \\
-1.5 \\
1.8 \\
2.3 \\
1.7\end{array}$ \\
\hline \multicolumn{11}{|c|}{ HYDROCELLULOSE } \\
\hline $\begin{array}{l}5 \mathrm{a} \\
5 \mathrm{~b} \\
5 \mathrm{c} \\
5 \mathrm{~d} \\
5 \mathrm{e} \\
5 \mathrm{f}\end{array}$ & $\begin{array}{l}280 \\
280 \\
280 \\
280 \\
280 \\
280\end{array}$ & $\begin{array}{l}80.0 \\
80.0 \\
80.0 \\
80.0 \\
80.0 \\
80.0\end{array}$ & $\begin{array}{r}35 \\
86 \\
72 \\
130 \\
120 \\
185\end{array}$ & $\begin{array}{r}35 \\
121 \\
193 \\
323 \\
443 \\
628\end{array}$ & $\begin{array}{r}4.3 \\
8.1 \\
9.3 \\
17.3 \\
13.1 \\
13.5\end{array}$ & $\begin{array}{r}4.3 \\
12.4 \\
21.7 \\
39.0 \\
52.1 \\
65.6\end{array}$ & $\begin{array}{r}40.6 \\
59.0 \\
62.4 \\
73.7 \\
76.7\end{array}$ & \begin{tabular}{r}
49.7 \\
32.3 \\
31.5 \\
\hdashline 20.9 \\
18.0
\end{tabular} & $\begin{array}{l}6.7 \\
6.9 \\
4.7 \\
4.0 \\
3.7\end{array}$ & $\begin{array}{r}3.0 \\
1.8 \\
1.4 \\
1.4 \\
1.6\end{array}$ \\
\hline \multicolumn{11}{|c|}{ VISCOSE RAYON } \\
\hline $\begin{array}{l}6 \mathrm{a} \\
6 \mathrm{~b} \\
6 \mathrm{c} \\
6 \mathrm{~d} \\
6 \mathrm{e} \\
6 \mathrm{f} \\
7\end{array}$ & $\begin{array}{l}280 \\
280 \\
280 \\
280 \\
280 \\
280 \\
295\end{array}$ & $\begin{array}{l}85.6 \\
85.6 \\
85.6 \\
85.6 \\
85.6 \\
85.6 \\
12.5\end{array}$ & $\begin{array}{r}7 \\
19 \\
22 \\
24 \\
65 \\
32 \\
57\end{array}$ & $\begin{array}{r}7 \\
26 \\
43 \\
72 \\
137 \\
169 \\
57\end{array}$ & $\begin{array}{r}3.3 \\
3.7 \\
5.3 \\
6.2 \\
16.3 \\
6.2 \\
45.3\end{array}$ & $\begin{array}{r}3.3 \\
7.0 \\
12.3 \\
18.5 \\
34.8 \\
41.0 \\
45.3\end{array}$ & $\begin{array}{c}19.6 \\
24.4 \\
39.5 \\
51.8 \\
52.6 \\
48.2\end{array}$ & $\begin{array}{c}61.7 \\
59.1 \\
48.4 \\
37.9 \\
37.1 \\
40.8\end{array}$ & $\begin{array}{r}11.7 \\
10.5 \\
8.7 \\
7.8 \\
8.1 \\
7.8\end{array}$ & $\begin{array}{l}7.0 \\
6.0 \\
3.4 \\
2.5 \\
2.2 \\
3.2\end{array}$ \\
\hline \multicolumn{11}{|c|}{ COTTON IMPREGNATED WITH $\mathrm{Na}_{2} \mathrm{CO}_{3}(7 \%)$} \\
\hline $\begin{array}{l}8 \mathrm{a} \\
8 \mathrm{~b}\end{array}$ & $\begin{array}{l}251 \\
291\end{array}$ & $\begin{array}{l}10.0 \\
10.0\end{array}$ & $\begin{array}{r}180 \\
30\end{array}$ & $\begin{array}{r}180 \\
a 210\end{array}$ & $\begin{array}{l}36.8 \\
14.6\end{array}$ & $\begin{array}{l}36.8 \\
51.4\end{array}$ & $\begin{array}{r}6.1 \\
15.3\end{array}$ & $\begin{array}{l}61.0 \\
54.6\end{array}$ & $\begin{array}{l}19.6 \\
22.7\end{array}$ & $\begin{array}{r}13.3 \\
7.4\end{array}$ \\
\hline \multicolumn{11}{|c|}{ COTTON IMPREGNATED WITH NaCl ( $8 \%)$} \\
\hline 9 & 280 & 7.1 & 120 & 120 & 49.3 & 49.3 & 12. 2 & 59.3 & 14. 9 & 13.6 \\
\hline
\end{tabular}

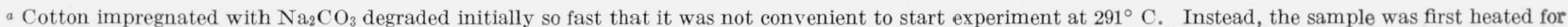

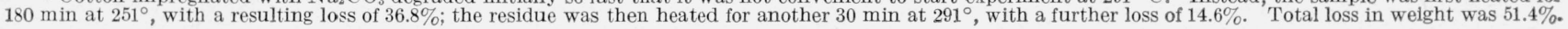


of cotton. Similarly, experiments 5 a to 5 f, inclusive, were carried out on the same specimen of hydrocellulose, and experiments $6 \mathrm{a}$ to $6 \mathrm{f}$ on the same specimen of viscose rayon. These three series of experiments were carried out at $280^{\circ} \mathrm{C}$. A sample of cotton impregnated with $\mathrm{Na}_{2} \mathrm{CO}_{3}(7 \%)^{6}$ was pyrolyzed in two consecutive steps, at $251^{\circ}$ and $291^{\circ} \mathrm{C}$. A sample of cotton impregnated with $\mathrm{NaCl}(8 \%)$ was pyrolyzed in one step at $280^{\circ} \mathrm{C}$. Fractions $\mathrm{V}_{25}$, on mass-spectrometer analysis, were found to consist mainly of water mixed with a small amount of acetaldehyde, as is shown later. Fractions $\mathrm{V}_{-80}$ and $\mathrm{V}_{-190}$, also on mass-spectrometer analysis, were found to consist of $\mathrm{CO}_{2}$ and $\mathrm{CO}$, respectively. According to table 1 , cotton and hydrocellulose behaved similarly on pyrolysis, whereas viscose rayon yielded more $\mathrm{H}_{2} \mathrm{O}, \mathrm{CO}_{2}$, and $\mathrm{CO}$, and less tar, than the first two cellulosic materials. The addition of $\mathrm{NaCl}$ or $\mathrm{Na}_{2} \mathrm{CO}_{3}$ had the effect of increasing the yields of $\mathrm{H}_{2} \mathrm{O}, \mathrm{CO}_{2}$, and $\mathrm{CO}$, and decreasing the yield of tar.

In table 2 cumulative yields of fractions are shown for $280^{\circ} \mathrm{C}$ (except in the case of purified cotton impregnated with $\mathrm{Na}_{2} \mathrm{CO}_{3}$, where the initial rate of degradation was so fast that the first $37 \%$ volatilization was carried out at $251^{\circ} \mathrm{C}$ and an additional $14 \%$ at $291^{\circ} \mathrm{C}$ ). The data shown in table 2 were

${ }_{6}$ The weight of the $\mathrm{Na}_{2} \mathrm{CO}_{3}$ was 7 percent of that of the dry cotton.

TABLE 2. Volatile fractions obtained in the pyrolysis of cellulose

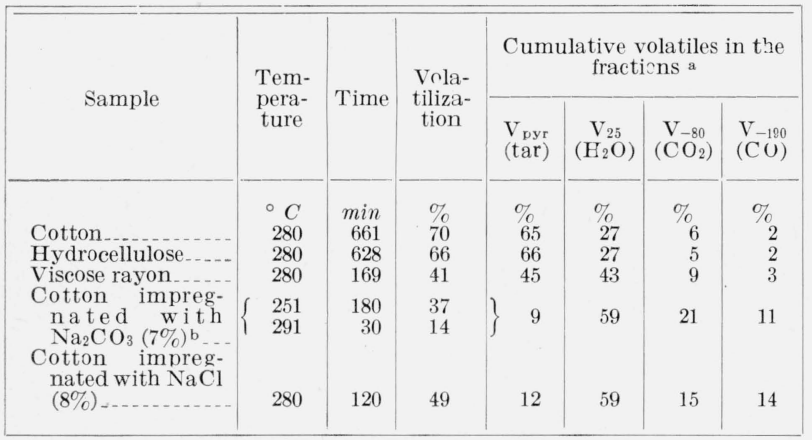

a In percentage of total volatiles.

b See footnote, table 1.

TABLE 3. Effect of temperature on yield of fractions in the pyrolysis of cellulose

\begin{tabular}{|c|c|c|c|c|c|c|c|}
\hline \multirow{2}{*}{ Material } & \multirow{2}{*}{$\begin{array}{l}\text { Experi- } \\
\text { ment }\end{array}$} & \multirow{2}{*}{$\begin{array}{l}\text { Tem- } \\
\text { pera- } \\
\text { ture }\end{array}$} & \multirow{2}{*}{$\begin{array}{l}\text { Vola- } \\
\text { tiliza- } \\
\text { tion, } \\
\text { cumu- } \\
\text { lative }\end{array}$} & \multicolumn{4}{|c|}{$\begin{array}{l}\text { Volatile fractions of total } \\
\text { volatilized part }\end{array}$} \\
\hline & & & & $\begin{array}{l}V_{\text {pyr }} \\
(\operatorname{tar})\end{array}$ & $\begin{array}{c}\mathrm{V}_{25} \\
\left(\mathrm{H}_{2} \mathrm{O}\right)\end{array}$ & $\begin{array}{l}\mathrm{V}_{-80} \\
\left(\mathrm{CO}_{2}\right)\end{array}$ & $\begin{array}{l}V_{-190} \\
(\mathrm{CO})\end{array}$ \\
\hline \multirow{2}{*}{ Cotton } & $\begin{array}{l}1 \\
2 \mathrm{a}\end{array}$ & $\begin{array}{l}{ }^{\circ} C \\
250 \\
280\end{array}$ & $\begin{array}{l}\% \\
2.7 \\
3.3\end{array}$ & $\begin{array}{l}\% \\
26 \\
34\end{array}$ & $\begin{array}{c}\% \\
54 \\
51\end{array}$ & $\begin{array}{l}\% \\
12 \\
10\end{array}$ & $\begin{array}{r}\% \\
8 \\
5\end{array}$ \\
\hline & $\mid \begin{array}{c}2 \mathrm{a} \text { to } 2 \mathrm{c} \\
3\end{array}$ & $\begin{array}{l}280 \\
321\end{array}$ & $\begin{array}{l}19.4 \\
22.0\end{array}$ & $\begin{array}{l}64 \\
65\end{array}$ & $\begin{array}{l}30 \\
28\end{array}$ & $\begin{array}{l}5 \\
4\end{array}$ & $\begin{array}{l}1 \\
3\end{array}$ \\
\hline Viscose rayon.- & $\left\{\begin{array}{c}6 \mathrm{a} \text { to } 6 \mathrm{f} \\
7\end{array}\right.$ & $\begin{array}{l}280 \\
295\end{array}$ & $\begin{array}{l}41.0 \\
45.3\end{array}$ & $\begin{array}{l}53 \\
48\end{array}$ & $\begin{array}{l}37 \\
41\end{array}$ & $\begin{array}{l}8 \\
8\end{array}$ & $\begin{array}{l}2 \\
3\end{array}$ \\
\hline
\end{tabular}

calculated on the basis of the data in table 1 , interpolating where necessary.

The temperature effect on yields of the various fractions is shown in table 3 , where a comparison is made of results obtained at different temperatures, but for about the same extent of degradation. According to this table the iemperature effect through a range of about $250^{\circ}$ to $321^{\circ} \mathrm{C}$ is not pronounced.

\section{Analysis of Fractions}

\subsection{Mass Spectrometer Analysis}

Mass-spectrometer analysis of fractions $\mathrm{V}_{-190}$ and $\mathrm{V}_{-80}$ showed them to consist of $\mathrm{CO}$ and $\mathrm{CO}_{2}$, respectively. Similar analysis for fraction $V_{25}$, as shown in table 4 , indicates that water is the main

TABLE 4. Mass-spectrometer analysis of fraction $\mathrm{V}_{25}$

\begin{tabular}{|c|c|c|c|c|c|}
\hline \multirow{2}{*}{ Component } & \multicolumn{2}{|c|}{$V^{\text {Viscose rayon }}{ }^{a}$} & \multirow{2}{*}{$\begin{array}{c}\text { Cotton } \\
\text { impreg- } \\
\text { nated } \\
\text { with } \\
\mathrm{NaCl}(8 \%)\end{array}$} & \multicolumn{2}{|c|}{$\begin{array}{l}\text { Cotton impreg- } \\
\text { nated with } \\
\mathrm{Na}_{2} \mathrm{CO}_{3}{ }^{a}(7 \%)\end{array}$} \\
\hline & 1 & 2 & & 1 & 2 \\
\hline $\begin{array}{l}\text { Water } \\
\text { Acetaldehyde }\end{array}$ & $\begin{array}{c}\text { Mole } \% \\
84 \\
16\end{array}$ & $\begin{array}{c}\text { Mole } \\
92 \\
8\end{array}$ & $\begin{array}{c}\text { Mole } \% \\
97 \\
3\end{array}$ & $\begin{array}{c}\text { Mole } \% \\
97 \\
3\end{array}$ & $\begin{array}{c}\text { Mole } \% \\
91 \\
9\end{array}$ \\
\hline
\end{tabular}

${ }^{a}$ Analyses 1 and 2 , in the case of viscose rayon, were made of fractions $\mathrm{V}_{25}$ from experiments $6 \mathrm{a}$ and 7 (table 1 ); in the case of cotton impregnated with $\mathrm{Na}_{2} \mathrm{CO}_{3}$ $(7 \%)$, analyses 1 and 2 were made of fractions $V_{25}$ from experiments $8 \mathrm{a}$ and $8 \mathrm{~b}$, respectively (table 1 ).

constituent. The only other constituent is acetaldehyde, which appears in amounts varying from 3 to 16 percent. The reason for this variation is not apparent from the present limited data.

Analysis of fraction $\mathrm{V}_{\mathrm{pyr}}$ (tar) was performed $\mathrm{by}$ Bradt and Mohler in a $60^{\circ}$ Nier mass spectrometer, using a method that they have developed [7]. The sample was heated in a vacuum tube furnace that opened directly into the ionization chamber, and the temperature was increased step by step until there was no further evaporation. Mass spectra were recorded at each step. In addition to fraction $\mathrm{V}_{\mathrm{pyr}}$, these investigators also vaporized or pyrolyzed directly into the mass spectrometer filter paper, purified cotton, viscose rayon, cellobiose, and levoglucosan. There are no background patterns of pure compounds available for mass-spectrometer analysis of these substances, and the conclusions drawn on the basis of the mass spectra obtained must therefore be considered as tentative.

Filter paper, cotton, and viscose rayon gave similar mass spectra. When heated above $100^{\circ} \mathrm{C}$ there was some evolution of $\mathrm{H}_{2} \mathrm{O}, \mathrm{CO}_{2}$, and $\mathrm{CO}$. At $240^{\circ}$ and higher, a rather complicated mass spectrum extending to mass 144 appeared. Cellobiose appeared to degrade at $250^{\circ} \mathrm{C}$, and the

7 The authors are indebted to P. Bradt and F. L. Mohler of the Mass Spectrom. etry Section of the Bureau for performing these analyses and for interpreting the results. 
spectrum showed small peaks, indicating masses heavier than 144. Its spectrum was much like those of the cellulosic materials.

Levoglucosan evaporated in a narrow temperature range at about $130^{\circ} \mathrm{C}$. Its mass spectrum showed peaks corresponding to $\mathrm{H}_{2} \mathrm{O}, \mathrm{CO}_{2}$, and $\mathrm{CO}$. These peaks were rather small as compared with those that were obtained for the celluloses.

The mass spectra obtained for fraction. $V_{\text {pyr }}$ (tar) from cotton and viscose rayon were similar. At an evaporation temperature of about $130^{\circ} \mathrm{C}$, these spectra were almost identical with that from levoglucosan. However, there was in the tar a compound that was less volatile than levoglucosan. and that degraded at higher temperatures to give a spectrum more like the product obtained from direct pyrolysis of cellulose into the mass spectrometer. It may be significant that all the spectra, whether from cellulose, levoglucosan, or tar, contained peaks for masses 126 and 144 . These masses correspond to that of levoglucosan or of the cellulose structural unit, molecular weight 162 , with 2 and 1 molecules of water, respectively, split off.

\subsection{Infrared Analysis of Fraction $\mathrm{V}_{\mathrm{pyr}}$}

Samples of pure levoglucosan and of fraction $V_{\text {py }}$ (tar) from cotton were dissolved in methanol. Thin films were deposited on rock salt by evaporating the solvent, and infrared absorption spectra of the resulting films were obtained. As shown in figure $2,^{8}$ the only significant difference between the two spectra is the presence of an absorption band at 5.78 microns in the spectrum of fraction $\mathrm{V}_{\mathrm{pyr}}$ (tar). This suggests that fraction $\mathrm{V}_{\mathrm{pyr}}$ contained both levoglucosan and a compound that contains $\mathrm{C}=\mathrm{O}$ groups.

8 Theauthors are indebted to Florence H. Forziati and Robert M. Brownell of the Textiles Section of the Bureau, for performing these infrared absorption of the Textiles Section of the Bureau, for
analyses and for interpreting the results.

\subsection{Average Molecular Weight of Fraction $\mathrm{V}_{\mathrm{pyr}}$}

The average molecular weight of fraction $V_{\text {pyr }}$ (tar) from cotton was determined by a microfreezingpoint lowering method from a solution in phenol. Four determinations were made on this fraction and four on pure levoglucosan as a control. The molecular freezing-point lowering for phenol is given in the literature as $7.3^{\circ} \mathrm{C}$. Sufficient sample was used in each determination to give a freezingpoint depression of approximately $3^{\circ} \mathrm{C}$. The molecular weight of levoglucosan was found to be $166 \pm 2$ as compared with 162 theoretical. The average molecular weight of fraction $V_{\text {pyr }}$ was found to be $152 \pm 1$.

\section{Rates of Degration and Activation Energies}

\subsection{Rate Measurements in a Spring Balance}

The rates of thermal degradation of cellulosic materials were determined by means of a very sensitive tungsten spring balance enclosed in a Pyrex housing, which could be evacuated to about $10^{-5} \mathrm{~mm}$ $\mathrm{Hg}$. This apparatus and the method have been described previously [6] in connection with a study of the thermal degradation of a number of polymers. The method, briefly, consists in heating a sample of about 4 to $6 \mathrm{mg}$ in a crucible suspended from the tungsten spring, and recording at regular intervals the loss in weight of the sample due to pyrolysis and evaporation, as indicated by a change in position of a crossline on a wire extension of the spring.

In preparing for a rate experiment the crucible containing the sample was suspended from the tungsten spring into a tube projecting down from the vacuum apparatus. The apparatus was pumped to a vacuum of approximately $10^{-6} \mathrm{~mm} \mathrm{Hg}$ and left standing. In the meantime an electric furnace, kept in a position away from the projected tube, was heated overnight to the temperature required for the given experiment. In the morning the furnace was

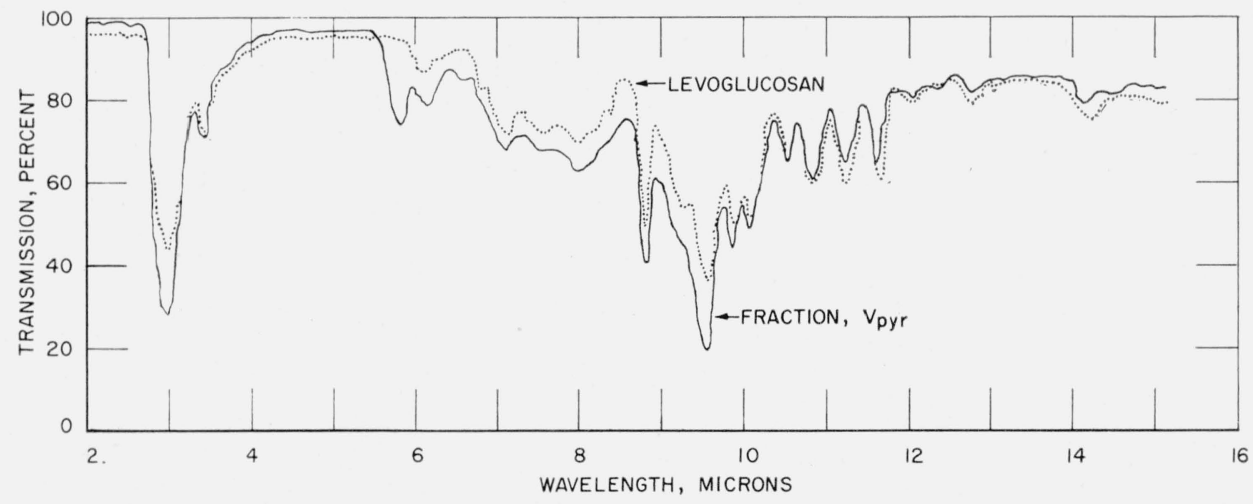

Figure 2. Infrared absorption spectra of the tarry fraction $\mathrm{V}_{\mathrm{pyr}}$ and of levoglucosan. 


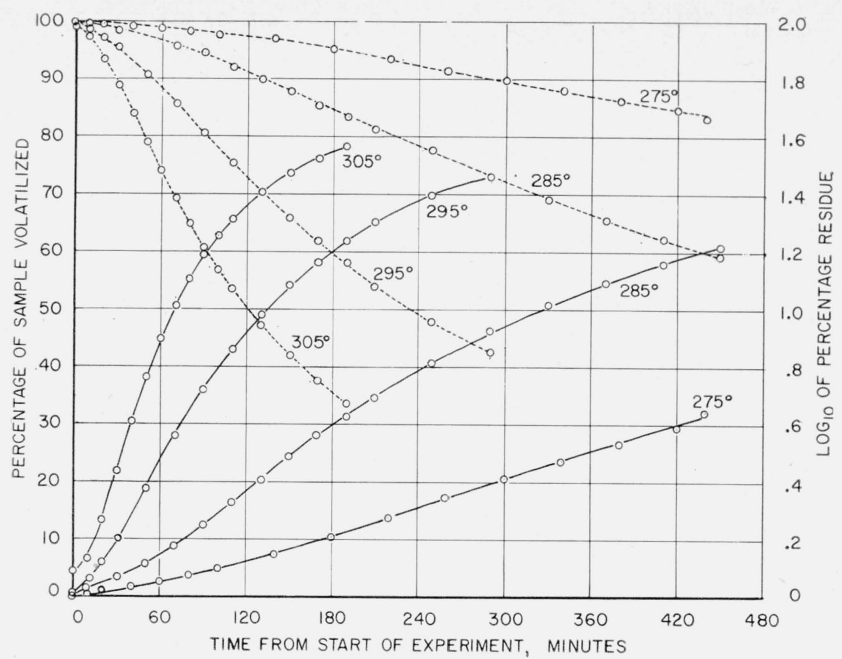

Figure 3. Thermal degradation of cotton.

- percentage of sample volatilized versus time; ......, $\log _{10}$ of percentage residue versus time.

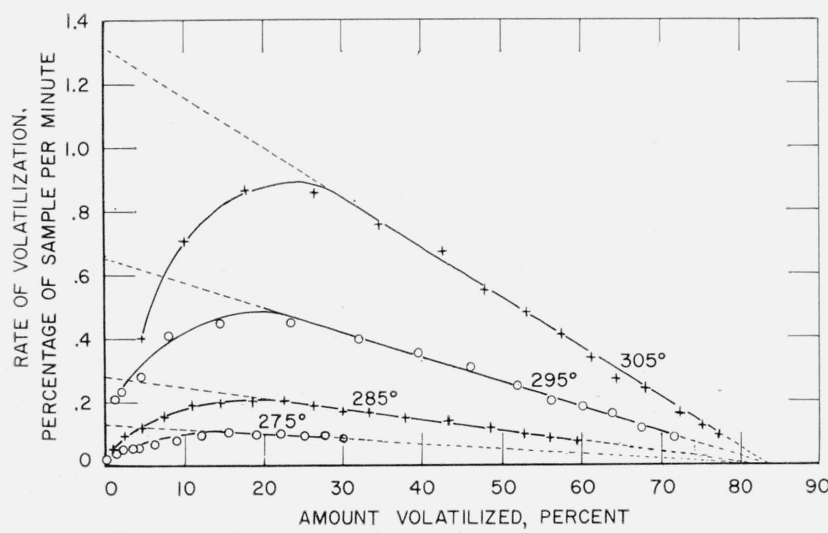

Figure 4. Rates of volatilization of cotton, in percentage of sample per minute, as a function of percentage volatilization ( $K_{1}$ rates).

Dotted lines represent extrapolations of the rate curves.

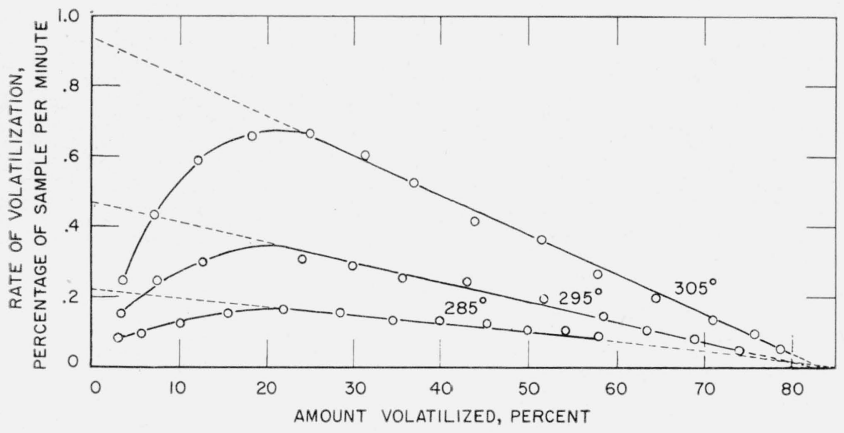

Figure 5. Rates of volatilization of hydrocellulose, in percent of sample per minute, as a function of percentage volatilization.

Dotted lines represent extrapolations of the rate curves.

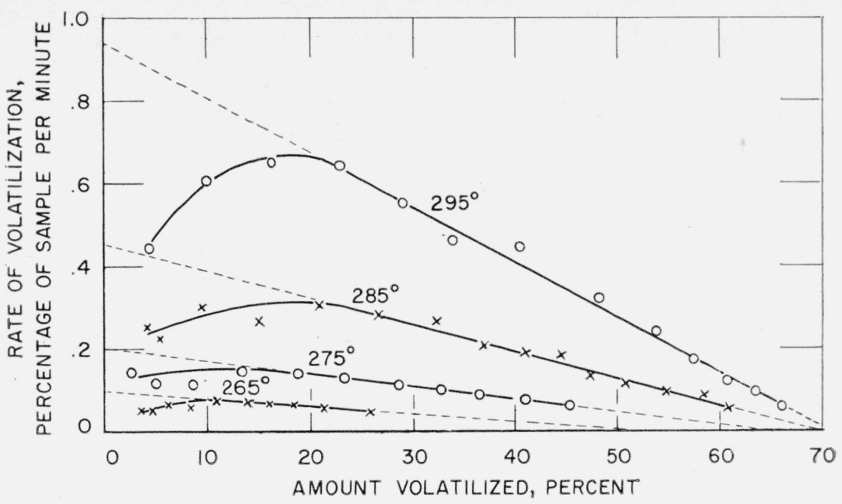

Figure 6. Rates of volatilization of viscose rayon, in percent of sample per minute, as a function of percentage volatilization.

Dotted lines represent extrapolations of the rate curves.

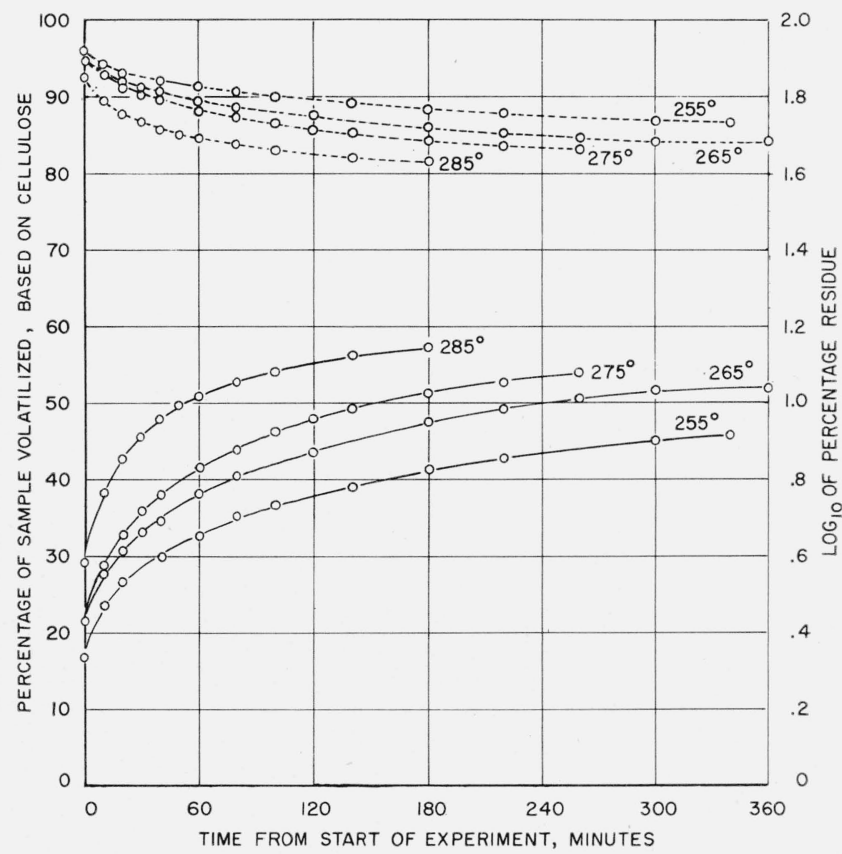

FIgure 7. Thermal degradation of cotton impregnated with $\mathrm{Na}_{2} \mathrm{CO}_{3}(9 \%)$.

$\longrightarrow$, percentage of sample volatilized versus time; ......, $\log _{10}$ of percentage residue versus time.

raised into position around the sample. It ordinarily took about $15 \mathrm{~min}$ for the crucible to reach the required temperature. Duration of the experiment was counted from the time this temperature was reached. The temperature was controlled by means of an electronic thermostat to within $\pm 0.2 \mathrm{deg}$ C.

The results of rate experiments on cotton are shown in figures 3 and 4 . The rates, $K_{1}$, in percentage of the original dried cellulose per minute, are initially low and pass through maxima, beyond 


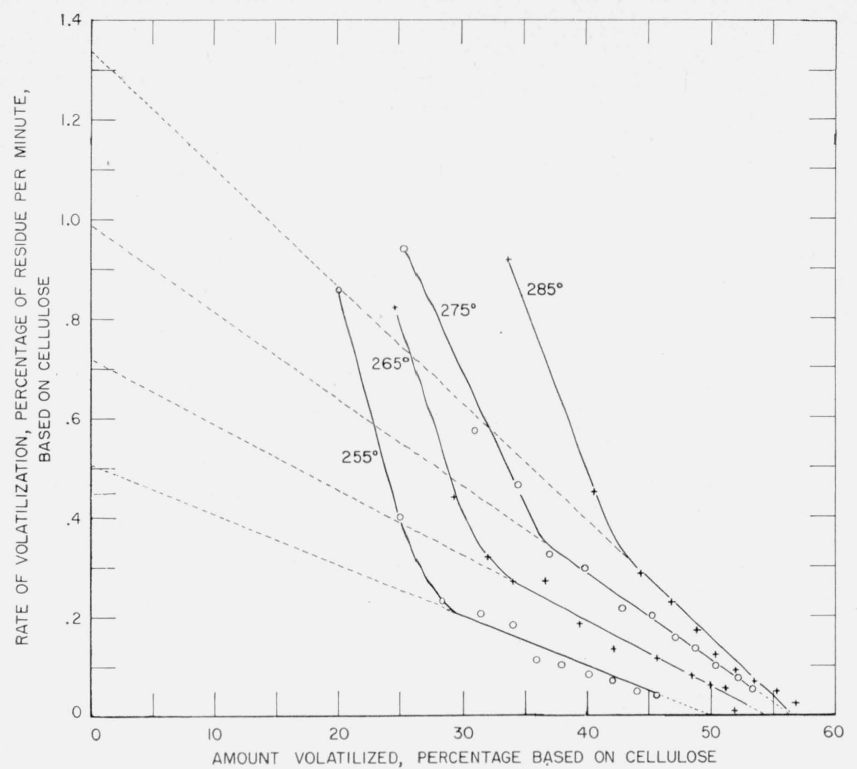

Figure 8. Rates of volatilization of cotton impregnated with $\mathrm{Na}_{2} \mathrm{CO}_{3}(9 \%)$, in percentage of cellulosic residue per minute, as a function of percentage volatilization $\left(K_{2}\right.$ rates $)$.

Dotted lines represent extrapolations of the rate curves.

which they follow straight lines. The points at which extrapolations of these lines intersect with the abscissas are defined as carbonization end points expressed in percentage of volatilization. The char yield, in percent of sample, for any particular temperature can be obtained by subtracting the carbonization end point from 100. By extrapolating the straight parts of the $K_{1}$ rate curves to the ordinate, the apparent initial rates were obtained. The importance of these apparent initial rates lies in the fact that the samples have the same composition only at zero degradation, and these rates can thus be used for the purpose of comparison or for calculating activation energies.

The curves obtained by plotting percentage of sample volatilized and logarithm of percentage residue against time for hydrocellulose and viscose rayon, were similar to the curves obtained for cotton, figure 2 , and are not shown here. The $K_{1}$ rate of volatilization curves for hydrocellulose and viscose rayon are shown in figures 5 and 6 , respectively. The apparent initial $K_{1}$ rates and the carbonization end points for hydrocellulose and viscose rayon were obtained by extrapolation, as in the case of cotton.

Results of rate experiments on cotton impregnated with $\mathrm{Na}_{2} \mathrm{CO}_{3}(9 \%)$ are shown in figures 7 and 8. The thermal stability of the cotton was greatly reduced as a result of the admixture with sodium carbonate. This reduction in stability was particularly great for the initial stages of the degradation. In the 15-min interval during which the cotton was raised from room temperature to the desired tem- perature, about 18 to 30 percent of the cotton volatilized, depending upon the final temperature.

The rate curves for $\mathrm{Na}_{2} \mathrm{CO}_{3}$-impregnated cotton are shown in figure 8 . In this case the rates were expressed in percentages of residues existing at the instant (excluding $\mathrm{Na}_{2} \mathrm{CO}_{3}$ ) instead of percentages of the original samples and are designated as $K_{2}$ rates. This was done for the reason that the $K_{2}$ plots are straight lines beyond 30 to 40 percent volatilization, while the $K_{1}$ plots are curved through their whole extent. Extrapolated initial rates are the same whether they are obtained from $K_{1}$ or $K_{2}$ rate curves.

The plots showing percentage volatilization versus time and logarithm of percentage residue versus time for viscose rayon impregnated with $\mathrm{Na}_{2} \mathrm{CO}_{3}$ $(9 \%)$ and cotton impregnated with $\mathrm{NaCl}(9 \%)$ are not shown here. These plots were similar to the corresponding plots for cotton impregnated with $\mathrm{Na}_{2} \mathrm{CO}_{3}(9 \%)$, shown in figure 7 . The $K_{2}$ rate curves for viscose rayon impregnated with $\mathrm{Na}_{2} \mathrm{CO}_{3}$ and cotton impregnated with $\mathrm{NaCl}$ are shown in figures 9 and 10, respectively. The straight parts of the $K_{2}$ plots in figures 9 and 10 were extrapolated to obtain the apparent initial rates and the carbonization end points. In all cases, the plots of logarithm of residue versus percentage volatilization (shown in figs. 3 and 7 as dotted lines), were not straight lines, indicating that the over-all degradation reaction is not of first order.

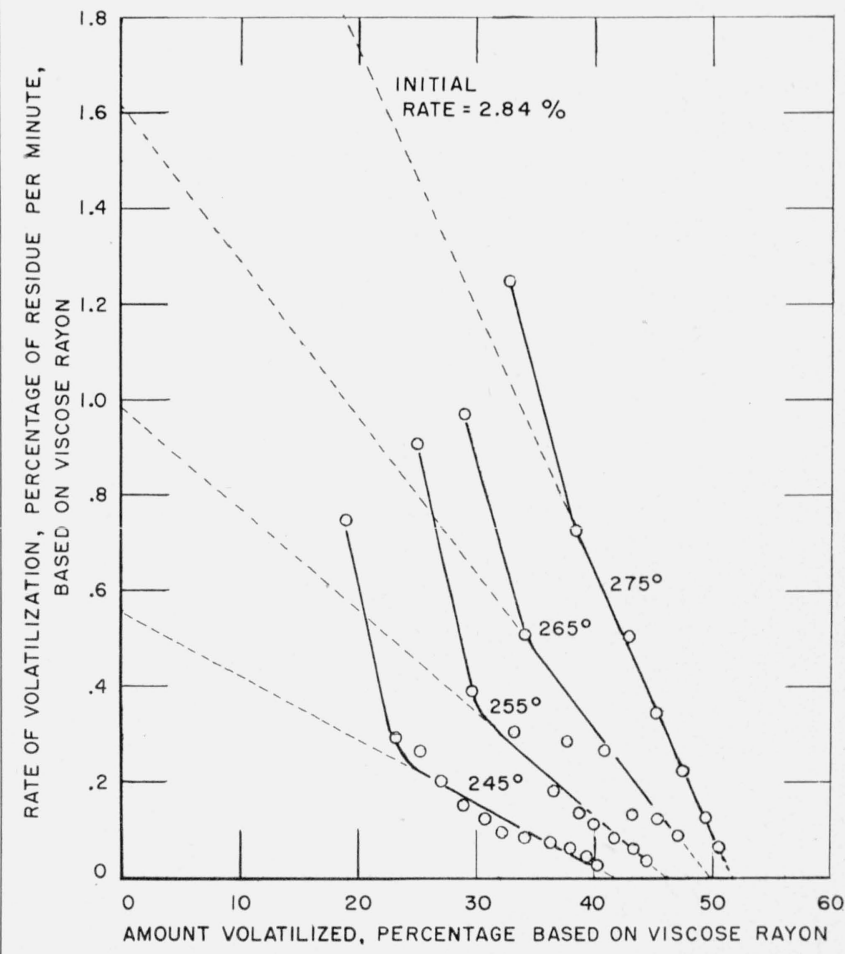

FIgURE 9. Rates of volatilization of viscose rayon impregnated with $\mathrm{Na}_{2} \mathrm{CO}_{3}(9 \%)$, in percentage of cellulosic residue per minute, as a function of percentage volatilization.

Dotted lines represent extrapolations of the rate curves. 


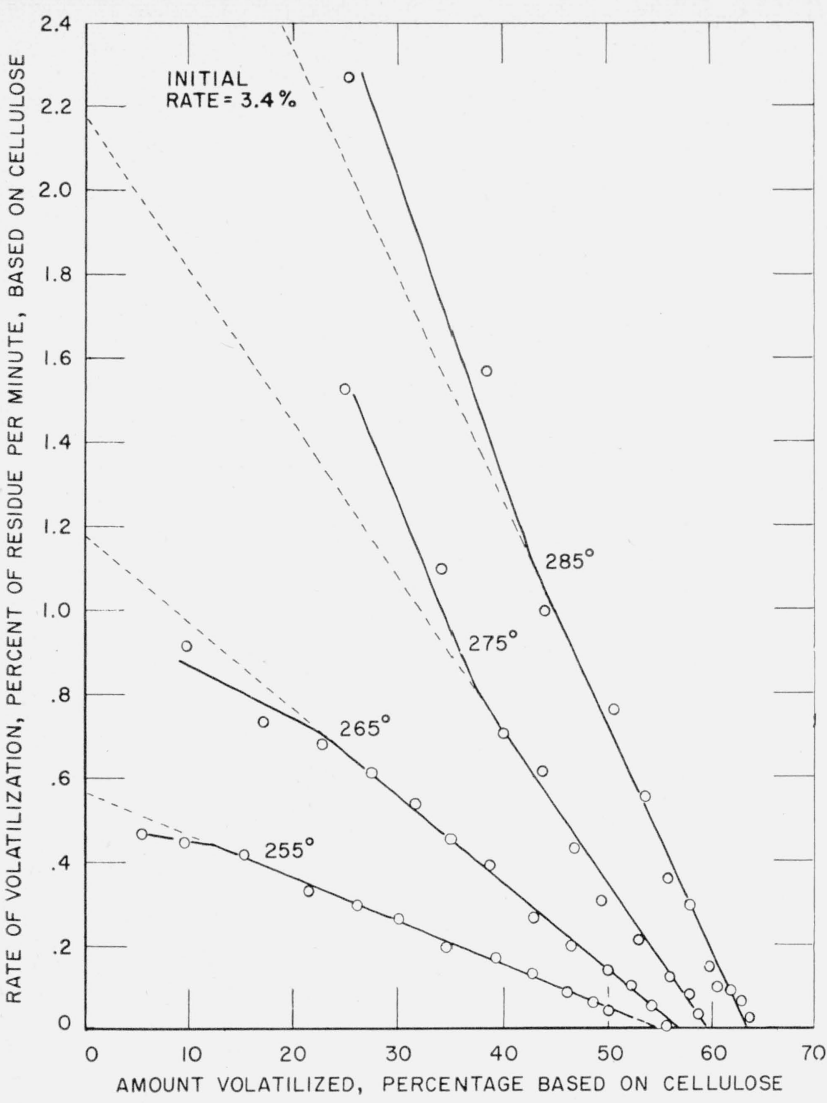

FIGURE 10. Rates of volatilization of cotton impregnated with $\mathrm{NaCl}(9 \%)$, in percentage of cellulosic residue per minute, as a function of percentage volatilization.

Dotted lines represent extrapolations of the rate curves.

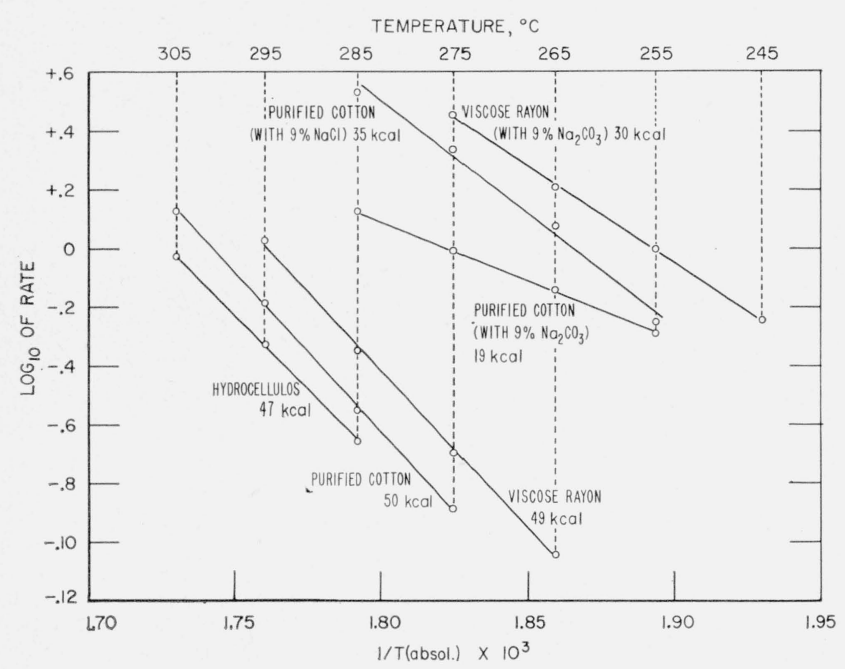

FIGURE 11. Activation energy of thermal degradation of cellulosic materials, based on extrapolated initial rates.
TABLE 5. Rates of thermal degradation of cellulose samples

\begin{tabular}{|c|c|c|c|c|c|}
\hline $\begin{array}{l}\text { Temper- } \\
\text { ature }\end{array}$ & $\begin{array}{c}\text { Heating } \\
\text { duration }\end{array}$ & $\begin{array}{c}\text { Loss of } \\
\text { weight } a\end{array}$ & $\begin{array}{l}\text { Apparent } \\
\text { initial rate }\end{array}$ & $\begin{array}{c}\text { Carboniza- } \\
\text { tion end } \\
\text { point }\end{array}$ & $\begin{array}{l}\text { Activation } \\
\text { energy }\end{array}$ \\
\hline \multicolumn{6}{|c|}{ COTTON } \\
\hline $\begin{array}{l}{ }^{\circ} C \\
275 \\
285 \\
295 \\
305\end{array}$ & $\begin{array}{r}\min \\
440 \\
450 \\
290 \\
193\end{array}$ & $\begin{array}{l}\% \\
32 \\
61 \\
73 \\
78\end{array}$ & $\begin{array}{c}\% / \min \\
0.13 \\
.28 \\
.65 \\
1.34\end{array}$ & $\begin{array}{l}\% \\
79 \\
81 \\
82 \\
83\end{array}$ & $\begin{array}{c}\text { kcal /mole } \\
50\end{array}$ \\
\hline \multicolumn{6}{|c|}{ HYDROCELLULOSE } \\
\hline $\begin{array}{l}285 \\
295 \\
305\end{array}$ & $\begin{array}{l}460 \\
460 \\
290\end{array}$ & $\begin{array}{l}60 \\
76 \\
80\end{array}$ & $\begin{array}{r}0.22 \\
.47 \\
.94\end{array}$ & $\begin{array}{l}82 \\
82 \\
83\end{array}$ & 47 \\
\hline \multicolumn{6}{|c|}{ VISCOSE RAYON } \\
\hline $\begin{array}{l}265 \\
275 \\
285 \\
295\end{array}$ & $\begin{array}{l}460 \\
440 \\
360 \\
240\end{array}$ & $\begin{array}{l}27 \\
46 \\
62 \\
67\end{array}$ & $\begin{array}{r}0.09 \\
.20 \\
.45 \\
.94\end{array}$ & $\begin{array}{l}51 \\
64 \\
69 \\
71\end{array}$ & 49 \\
\hline \multicolumn{6}{|c|}{ COTTON IMPREGNATED WITH $\mathrm{Na}_{2} \mathrm{CO}_{3}(9 \%)$} \\
\hline $\begin{array}{l}255 \\
265 \\
275 \\
285\end{array}$ & $\begin{array}{l}340 \\
360 \\
260 \\
180\end{array}$ & $\begin{array}{l}46 \\
52 \\
54 \\
57\end{array}$ & $\begin{array}{r}0.51 \\
.72 \\
.98 \\
1.34\end{array}$ & $\begin{array}{l}49 \\
54 \\
56 \\
57\end{array}$ & 19 \\
\hline \multicolumn{6}{|c|}{ VISCOSE RAYON IMPREGNATED WYTH $\mathrm{Na}_{2} \mathrm{CO}_{3}(9 \%)$} \\
\hline $\begin{array}{l}245 \\
255 \\
265 \\
275\end{array}$ & $\begin{array}{l}300 \\
220 \\
140 \\
120\end{array}$ & $\begin{array}{l}41 \\
45 \\
48 \\
51\end{array}$ & $\begin{array}{r}0.55 \\
.99 \\
1.61 \\
2.84\end{array}$ & $\begin{array}{l}42 \\
46 \\
50 \\
52\end{array}$ & 30 \\
\hline \multicolumn{6}{|c|}{ COTTON IMPREGNATED WITH NaCl $(9 \%)$} \\
\hline $\begin{array}{l}255 \\
265 \\
275 \\
285\end{array}$ & $\begin{array}{l}420 \\
340 \\
240 \\
240\end{array}$ & $\begin{array}{l}51 \\
56 \\
59 \\
64\end{array}$ & $\begin{array}{l}0.56 \\
1.18 \\
2.18 \\
3.40\end{array}$ & $\begin{array}{l}55 \\
57 \\
60 \\
64\end{array}$ & 35 \\
\hline
\end{tabular}

a Referred to dry cellulose.

Pertinent data on all the rate experiments by the loss-of-weight method in the tungsten-spring apparatus, are shown in table 5. The activation energies are shown in the last column of this table. These activation energies were obtained graphically, as shown in figure 11 , by plotting the $\log _{10}$ of the apparent initial rate at any given temperature versus $1 / T \times 10^{3}$, where $T$ is the absolute temperature. The over-all activation energy, $E$, in kilocalories per mole, is the slope of the straight line, obtained from the formula

$$
E=-\frac{d \log K}{d(1 / T)} \times 4.57 \times 10^{-3} .
$$

A comparison of initial rates for all the materials investigated is given in table 6 for $275^{\circ}$ and $285^{\circ} \mathrm{C}$, the two temperatures at which the most complete data were obtained. Table 7 gives a condensed summary of data showing the effect of additions of $\mathrm{Na}_{2} \mathrm{CO}_{3}$ and $\mathrm{NaCl}$ on the yield of flammable and nonflammable fractions in the pyrolysis of cellulosic materials in a vacuum. 
TABLE 6. Comparison of rates of thermal degradation of cellulose samples at $275^{\circ}$ and $285^{\circ} \mathrm{C}$

\begin{tabular}{|c|c|c|}
\hline \multirow{2}{*}{ Sampla } & \multicolumn{2}{|c|}{$\begin{array}{l}\text { Initial rates, in percent } \\
\text { of sample per min, at- }\end{array}$} \\
\hline & $275^{\circ}$ & $285^{\circ}$ \\
\hline $\begin{array}{l}\text { Cotton } \\
\text { Hydrocellulose } \\
\text { Viscose rayon } \\
\text { Cotton impregnated with } \mathrm{Na}_{2} \mathrm{CO}_{3}(9 \%) \\
\text { Viscose rayon impregnated with } \mathrm{Na}_{2} \mathrm{CO}_{3}(9 \%) \\
\text { Cotton impregnated with } \mathrm{NaCl}(9 \%)\end{array}$ & $\begin{array}{r}0.13 \\
a .10 \\
.20 \\
.98 \\
2.84 \\
2.18\end{array}$ & $\begin{array}{r}0.28 \\
.22 \\
.45 \\
1.34 \\
\text { a } 5.48 \\
3.40\end{array}$ \\
\hline
\end{tabular}

a Calculated on the basis of activation energy.

TABLE 7. Flammable and nonflammable volatile products and char obtained in the vacuum pyrolysis of cellulose materials (temperature of pyrolysis, $280^{\circ} \mathrm{C}$ )

\begin{tabular}{|c|c|c|c|c|c|c|c|}
\hline \multirow{2}{*}{ Material } & \multicolumn{3}{|c|}{ Flammable } & \multicolumn{3}{|c|}{ Nonflammable } & \multirow{2}{*}{ Char ${ }^{a}$} \\
\hline & Tar & $\mathrm{CO}$ & Total & $\mathrm{H}_{2} \mathrm{O}$ & $\mathrm{CO}_{2}$ & Total & \\
\hline $\begin{array}{l}\text { Cotton } \\
\text { Hydrocellulose } \\
\text { Viscose rayon } \\
\text { Cotton impregnated with } \\
\quad \mathrm{Na}_{2} \mathrm{CO}_{3}{ }^{b} \\
\mathrm{Cotton} \\
\mathrm{NaCl}\end{array}$ & $\begin{array}{r}\% \\
52 \\
53 \\
30 \\
5 \\
7\end{array}$ & $\begin{array}{r}\% \\
2 \\
2 \\
2 \\
6 \\
9\end{array}$ & $\begin{array}{l}\% \\
54 \\
55 \\
32 \\
11 \\
16\end{array}$ & $\begin{array}{l}\% \\
21 \\
21 \\
29 \\
33 \\
37\end{array}$ & $\begin{array}{r}\% \\
5 \\
4 \\
6 \\
\\
12 \\
9\end{array}$ & $\begin{array}{l}\% \\
26 \\
25 \\
35 \\
45 \\
46\end{array}$ & $\begin{array}{l}\% \\
20 \\
20 \\
33 \\
44 \\
\\
38\end{array}$ \\
\hline
\end{tabular}

$a$ Since the carbonization end points were not determined experimentally at $280^{\circ} \mathrm{C}$, the char values for this temperature were estimated from figures $4,5,6,8$, and 10 .

${ }_{b}$ Residue from pyrolysis for $180 \mathrm{~min}$ at $251^{\circ}$ was pyrolyzed further for $30 \mathrm{~min}$ at $291^{\circ}$. Volatilization in the second step was from $36.8 \%$ (volatilized in the first step) to $51.4 \%$, i. e., $14.6 \%$ (see table 1 ).

\subsection{Rates Calculated from Pyrolysis Data}

The data obtained in the step pyrolysis experiments at $280^{\circ} \mathrm{C}$, shown in table 1 , for cotton, hydrocellulose, and viscose rayon, were used in calculating the rates of volatilization in terms of averages for each individual step. Because in the pyrolysis experiments the degradation products were collected, weighed, and analyzed, it was possible to calculate rates of volatilization for each fraction, as well as for the total volatiles. These rates are shown plotted against percentage volatilization at $280^{\circ} \mathrm{C}$ in figures $12,13,14$, and 15 , for fractions $\mathrm{V}_{\mathrm{pyr}}, \mathrm{V}_{25}, \mathrm{~V}_{-80}$, and

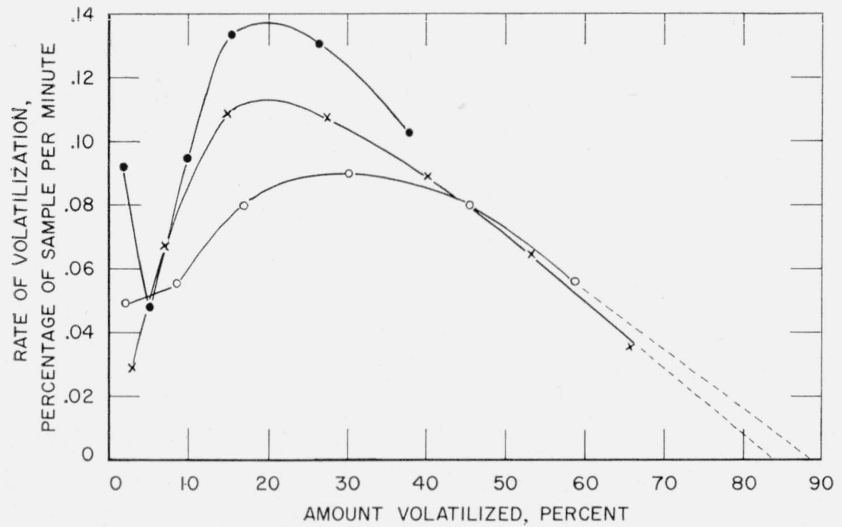

Figure 12. Rates of volatilization at $280^{\circ} \mathrm{C}$ calculated from pyrolysis data.

Rates of volatilization of the tarry fraction $\mathrm{V}_{\mathrm{pyr}}$, in percent of sample per minute, as a function of percentage volatilization for: and $\bigcirc$, hydrocellulose.

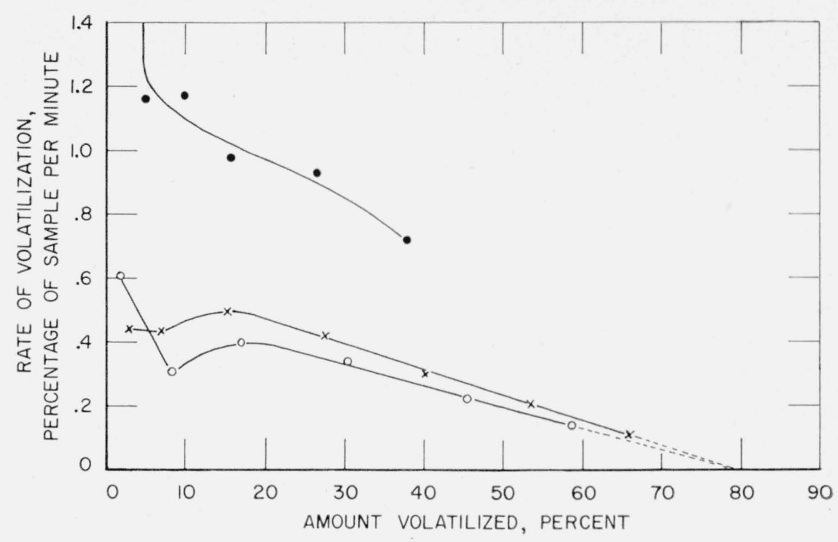

FIGURE 13. Rates of volatilization at $280^{\circ} \mathrm{C}$ calculated from pyrolysis data.

Rates of volatilization of fraction $\mathrm{V}_{25}$, in percentage of samnle per minute, as a

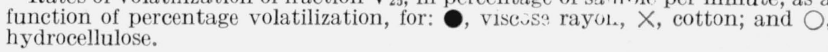

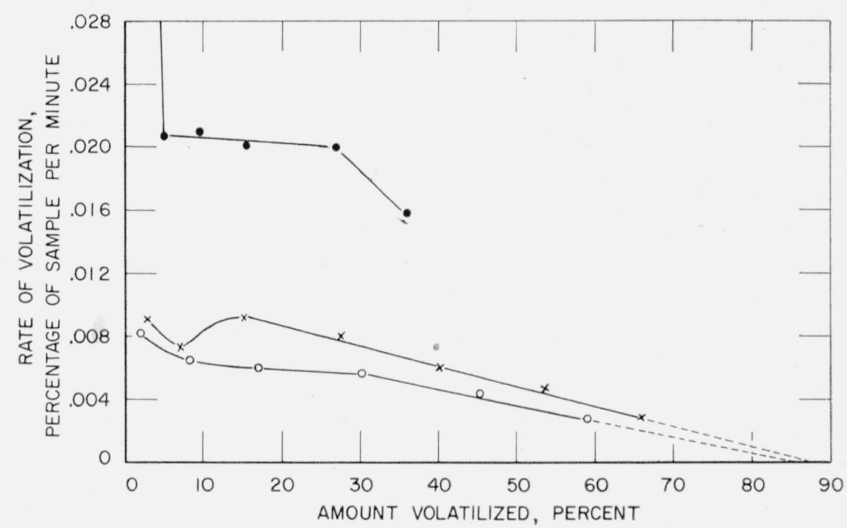

FIGURE 14. Rates of volatilization at $280^{\circ} \mathrm{C}$ calculated from pyrolysis data. Rates of volatilization of fraction $V_{-80}$, in percentage of sample per minute,
as a function of percentage volatilization, for: viscose rayon; $\times$, cotton; and , hydrocellulose.

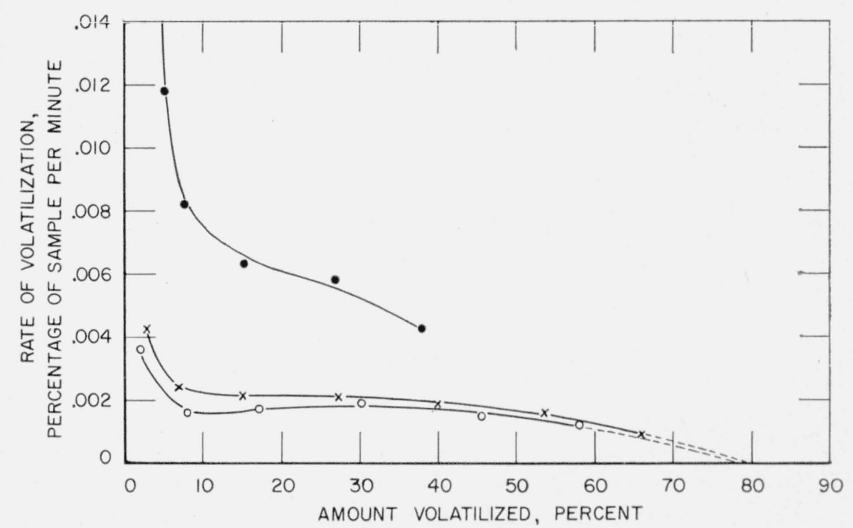

FiguRe 15. Rates of volatilization at $280^{\circ} \mathrm{C}$, calculated from pyrolysis data.

Rates of volatilization of fraction $\mathrm{V}_{-190}$, in percentage of sample per minute, as a function of percentage volatilization, for: 0 , viscose rayon; $X$, cotton; and $\bigcirc$, hydrocellulose. 


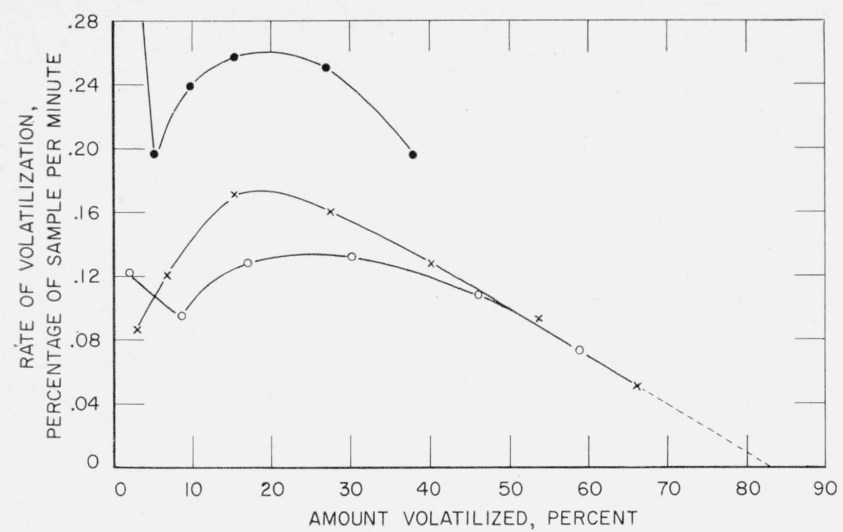

Figure 16. Rates of volatilization at $280^{\circ} \mathrm{C}$, calculated from pyrolysis data.

Over-all rates of volatilization, in percentage of sample per minute, as a function of percentage volatilization, for: viscose rayon; $X$, cotton, and $O$, hydrocellulose.

$\mathrm{V}_{-190}$, respectively, and in figure 16 for the total volatiles. The rates shown in figure 16 do not differ much from the $K_{1}$ rates determined in the springbalance apparatus and shown in figures 4,5 , and 6 . Extrapolation of the rate curves for cotton and hydrocellulose in figures $12,13,14,15$, and 16 leads to similar carbonization end points as were found in the spring-balance rate experiments. In the case of viscose rayon, where pyrolysis at $280^{\circ} \mathrm{C}$ was carried only to 41 percent volatilization, the carbonization end point is not shown.

\section{Discussion}

Although the cotton used in this work had a lower crystallinity and higher degree of polymerization than the hydrocellulose, there is little difference in their behavior on pyrolysis, whether in regard to ratio of products or to rates of degradation. The crystalline forces seem to weaken at the pyrolysis temperature, and, therefore, have little effect on the results of pyrolysis. As to the effect of chain length, it was shown previously [8] in the case of a number of polymers that long chains break up on heating during the initial stage of thermal degradation, even before volatilization occurs. This tends to eliminate the effect of chain length on pyrolysis, except where polymers of very low degree of polymerization are involved. Viscose rayon has low crystallinity and low degree of polymerization, and the type of its crystalline structure is different from that of cotton and hydrocellulose. Results of pyrolysis of viscose rayon indicate a lower yield of tar, a higher yield of $\mathrm{H}_{2} \mathrm{O}, \mathrm{CO}_{2}$, and $\mathrm{CO}$, and a faster rate of degradation than is the case with cotton and hydrocellulose. Further work will be required to determine the causes of the differences observed.

The presence of $\mathrm{Na}_{2} \mathrm{CO}_{3}$ or $\mathrm{NaCl}$ in intimate contact with the cellulose has a profound effect on the results of pyrolysis of cellulose. The tar yield is drastically reduced whereas the vield of $\mathrm{H}_{2} \mathrm{O}, \mathrm{CO}_{2}$, and $\mathrm{CO}$ is increased. Although the actual initial rates in the case of pure substances are low, rising to a maximum at about 15 to 20 percent volatilization, these rates in the presence of $\mathrm{Na}_{2} \mathrm{CO}_{3}$ and $\mathrm{NaCl}$ start extremely fast and do not show any maxima. The apparent initial rates are also much higher in the presence of the salts than is the case witb the untreated suinstances.

As shown in table 7 , the char yield is about the same for cotton and hydrocellulose. In the presence of salts, the char yield is about doubled. In the case of viscose rayon the char yield is about 1.5 times as much as in cotton or hydrocellulose.

In the pyrolysis of untreated celluloses, up to about 20 percent volatilization, the yield of tar rises gradually, whereas the revarse is true of the yields of $\mathrm{H}_{2} \mathrm{O}, \mathrm{CO}_{2}$, and $\mathrm{CO}$. Beyond about 20 percent volatilization the yields are stabilized and reach constant values. The data are insufficient to show whether the same is true with regard to the salt-impregnated celluloses.

Mass-spectrometer, infrared, and cryoscopic analysis of fraction $V_{\text {pyr }}$, all point to the conclusion that this fraction consists mainly of levoglucosan. However, there are definite indications that there is present in fraction $\mathrm{V}_{\mathrm{pyr}}$, in addition to levoglucosan, some small amount of other compound or compounds. These indications are: (1) a small part of fraction $\mathrm{V}_{\text {pyr }}$ is insoluble in $\mathrm{H}_{2} \mathrm{O}$, although all of it is soluble in methanol; (2) the infrared absorption spectrum of fraction $V_{\text {pyr }}$ differs from that of levoglucosan in having an absorption band at $5.78 \mu$; (3) there are some differences in the mass spectra of fraction $V_{\text {pyr }}$ and levoglucosan.

As shown in table 7 , the yield of fraction $V_{\text {pyr }}$ (tar) is 52 percent and 53 percent for cotton and hydrocellulose, respectively. This means that approximately 1 out of every 2 structural units in these celluloses vaporizes as a levoglucosan molecule. In viscose rayon, which yields 30 percent tar, approximately 1 out of every 3 structural units appears in the distillate as levoglucosan. The next largest volatile fraction is $\mathrm{H}_{2} \mathrm{O}$, which amounts to 21 percent for cotton and hydrocellulose, and 29 percent for viscose rayon. After discounting the hydrogen and oxygen that vaporize from cellulose as parts of levoglucosan, the highest possible theoretical yield of $\mathrm{H}_{2} \mathrm{O}$ from the other cellulose structural units would be 27 percent from cotton and hydrocellulose and 37 percent from viscose rayon. The difference between the theoretical and actual yield of $\mathrm{H}_{2} \mathrm{O}$ in the pyrolysis of the celluloses is accounted for by the formation of $\mathrm{CO}_{2}$ and $\mathrm{CO}$, and by the presence of $\mathrm{H}$ and $\mathrm{O}$ in the char. That the chars obtained at the carbonization end points at $280^{\circ} \mathrm{C}(20 \%$ for cotton or cellulose and $33 \%$ for viscose rayon, as given in table 7) contained volatile material was shown by experiments in which these chars were 
heated in a quartz tube in a vacuum by means of a Meker burner to about $1,000^{\circ} \mathrm{C}$. The loss in weight of the chars was roughly one-half for all the three celluloses.

The results of pyrolysis suggest the following possible mechanism for the thermal degradation of cellulose in a vacuum. A dehydration process takes place randomly along the chain. Another process, which takes place simultaneously, consists in thermal scissions of the polymer chain resulting in the formation of levoglucosan, $\mathrm{H}_{2} \mathrm{O}, \mathrm{CO}_{2}$, and $\mathrm{CO}$. The $\mathrm{C}-\mathrm{O}$ bonds in the chain are less stable thermally than the $\mathrm{C}-\mathrm{C}$ bonds. This was shown by the present authors in a series of experiments on the pyrolysis of polyethylene, and polyethylene oxide. The polyethylene oxide was found to have a lower thermal stability and a lower activation energy of thermal degradation than polyethylene. The various $\mathrm{C}-\mathrm{O}$ bonds in the chain are indicated in the structural formula (1) of the polymer as $\mathrm{k}, \mathrm{l}, \mathrm{m}$, and $\mathrm{n}$.

Random scissions of bonds $\mathrm{k}, \mathrm{l}$, or $\mathrm{n}$ result in a more or less complete breakdown of a part of the chain, yielding $\mathrm{H}_{2} \mathrm{O}, \mathrm{CO}_{2}, \mathrm{CO}$, and $\mathrm{C}$. A random scission of the $\mathrm{C}-\mathrm{O} \mathrm{m}$ bond may result in the formation of oxygen linkage between carbons 1 and 6 by a process analogous to the formation of levoglucosan from phenyl- $\beta$-D-glucoside. McCloskey and Coleman [9] have shown in formula (2) that this reaction takes place in two steps.

Whether in the pyrolysis of cellulose this process takes place in one step [10], formula (3), or in two steps, is problematical. Pyrolysis is unlike hydrolysis in an aqueous alkaline medium and a close analogy between the two reactions is not justified. The formation of levoglucosan units in cellulose pyrolysis takes place when scission of the $\mathrm{C}-\mathrm{O}$ $m$ bonds occur one structural unit awav from the ends formed through a random scission of a $\mathrm{C}-\mathrm{O} \mathrm{m}$ bond.

The presence of $\mathrm{Na}_{2} \mathrm{CO}_{3}$ and $\mathrm{NaCl}$ may have a catalytic effect on the dehydration and bond scissions taking place inside and outside the rings in the cellulose chain, resulting in increased yield of $\mathrm{H}_{2} \mathrm{O}$. $\mathrm{CO}_{2}$, and $\mathrm{CO}$ at the expense of levoglucosan, and also in an increased rate of degradation of the celluloses, particularly in the initial stages.

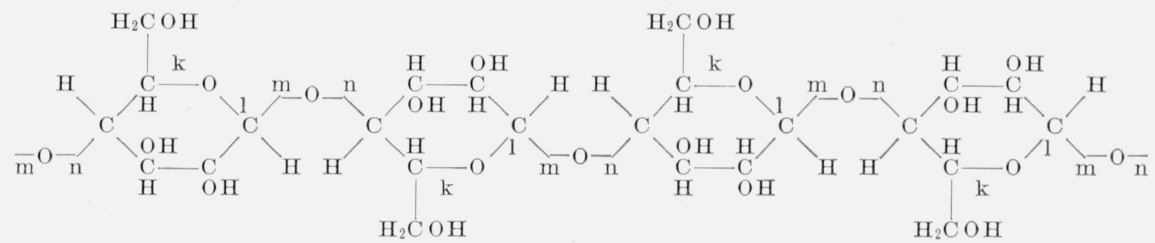<smiles>O=CC(O)C(O)C(O)C(O)C(=O)O</smiles>

Phenyl- $\beta$-D-glucoside

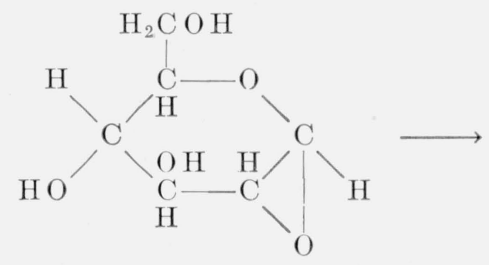

1,2-Anhydro sugar<smiles>OC[C@@H](O)[C@@H](O)C(O)O</smiles>

Levoglucosan

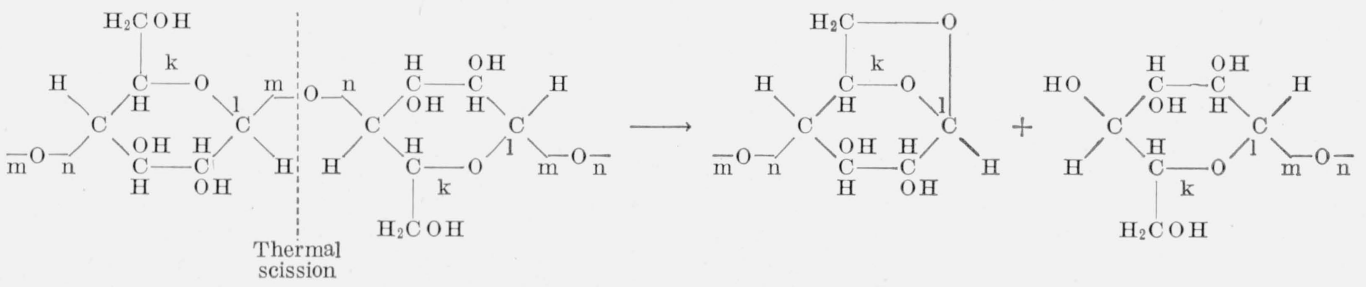




\section{References}

[1] J. Sarasin, Archiv. Sci. Phys. Nat. IV, 465 (1918).

[2] A. Pictet and J. Sarasin, Helv. Chim. Acta 1, 87-96 (1918).

[3] H. J. P. Venn, J. Textile Inst. 15, T414-T418 (1924).

[4] K. Tamaru, Bul. Chem. Soc. Japan 24, 164-8 (1951).

[5] S. L. Madorsky, V. E. Hart, S. Straus, and V. A. Sedlak, J. Research NBS 51, 327 (1953) RP2461.

[6] S. L. Madorsky, J. Polymer Sci. 9, 133 (1952); 11, 491 (1953).

[7] P. Bradt and F. L. Mohler, J. Research NBS 55, 323 (1955) RP2637.
[8] S. L. Madorsky and S. Straus, J. Research NBS 53, 361 (1954) RP2553.

[9] C. M. McCluskey and G. H. Coleman, J. Org. Chem, 10, 184 (1945).

[10] W. G. Parks, R. M. Esteve, jr., M. H. Gollis, R. Guercia, and A. Petrarca, paper presented at the 127th Meeting of the American Chemical Society, Cincinnati, Ohio, March 29 to April 7, 1955.

Washington, March 12, 1956. 